\title{
Evidence for color vision in the prairie dog (Cynomys ludovicianus)'
}

\author{
ROY E. CAIN and RICHARD H. CARLSON, Texas \\ Technological College, Lubbock, Tex. 79409
}

An experiment was performed to determine whether prairie dogs could use color information. By means of a WGTA four prairie dogs (Cynomys ludovicianus) were presented with two-choice color discrimination problems. Criterion for learning was set at $90 \%$ correct responses. Results indicate that some discriminations were learned more quickly than others, but criterion was reached on all possible combinations of red. yellow, blue, and green hues when brightness was irrelevant, indicating good color vision for this species.

Rodents, with the exception of some members of the family Sciuridae, are generally considered deficient in color vision (Reuck \& Knight, 1965). Among the family Sciuridae, ground squirrels (Arden \& Tansley, 1955b), chipmunks (Tansley, Copenhaver, \& Gunkel, 1961), prairie dogs (Walls, 1942), and some tree squirrels (Arden \& Silver, 1962) are reported to possess pure-cone retinae. But mere possession of color receptors does not necessarily mean that an animal uses color information. Some or all of the information in the response of photoreceptors may be lost at higher levels in the nervous system. However, Crescitelli \& Pollack (1965) were able to condition Antelope ground squirrels to discriminate blue light from various other wavelengths, including white light. Michels \& Schumacher (1968) have reported similar results for tree squirrels. Behavioral tests are the only means of determining whether or not a species actually uses color information.

With the exception of a few histological studies, the visual system of the prairie dog has not been explored. These diurnal sciurids make excellent laboratory animals and are easily trained using operant conditioning procedures. Since prairie dogs have pure-cone retinae (Walls, 1942) they should be capable of discriminating colors. The present research was designed to investigate the ability of prairie dogs to use color information to solve a variety of color discrimination problems.

\section{METHOD}

Four experimentally naive Black-tailed prairie dogs (Cynomys ludovicianus), one male and three females, were maintained at $80 \%$ normal laboratory body weight. In addition, Ss were approximately $22-\mathrm{h}$ food deprived before each test session.

The apparatus was a modified Wisconsin General Test Apparatus (WGTA). One side of the device contained twin translucent panels, each of which covered an opening leading to a circular foodwell. A vertically sliding wooden door separated $S$ from the stimulus panels between trials. Stimulus panels consisted of translucent Plexiglas, behind which were placed Kodak Wratten color filters (No. 8, 24, 47B, 58). Panels were designed so that they could be rapidly interchanged from one side to the other. Each panel was illuminated from the rear by a Kodak Carousel projector equipped with identical lenses and light sources $(425 \mathrm{~W})$. Variations in brightness of the discriminative stimuli were produced by means of neutral filters with densities of $0.1 .0 .4,0.7,0.9$, and 1.0 (Kodak Wratten Neutral Density Filters, No. 96).

The relative brightnesses of the discriminative stimuli were first physically equated for intensity by means of a photoelectric exposure meter and by matching polaroid black and white photographs. Since the relative brightness levels were not matched for the individual animal, it was further necessary to randomly vary the intensities of the two stimuli such that one stimulus was "brighter" than the other $50 \%$ of the time and "dimmer" $50 \%$ of the time. By means of neutral density filters, each wavelength was used in combination with filters ranging in density from 0 (no filter) to 1.0 (10\% transmittance). Such a wide range of brightness levels randomly presented assured that any discrimination based on brightness cues were reduced to near chance levels.

For two Ss (Prairie dogs 3 and 4) an additional step was added to the procedure which further tested for possible brightness discrimination. This procedure involved the addition of three new intensity levels (both brighter and dimmer) to the original six after criterion had been reached. A change in performance would have reflected possible brightness cues.

Experimental training consisted of one daily test session of 50 trials. Each $S$ was removed from the home cage and placed in the WGTA for a few minutes before the daily session. Room lights were dimmed and the panels illuminated with the appropriate colors. At the beginning of each trial one foodwell was baited with a food pellet; the other contained nothing. The position of the stimulus colors were varied in accordance with the Gellerman sequence (Gellerman, 1933) and the brightnesses were randomized. The opaque guillotine door was raised and $S$ permitted to make one choice. A response was defined as the first foodwell uncovered. $S$ was not allowed to correct errors. Criterion was set at 45 correct responses out of 50 trials ( $90 \%$ correct responses) or 500 trials, whichever came first. Each S solved four problems (Table 1).

\section{RESULTS AND DISCUSSION}

The results are summarized in Table 1 . Each animal was able to solve all of the required problems, but there were obvious differences in difficulty level. Those problems requiring $S$ to discriminate green from yellow were most difficult (Fig. 1), whereas those problems requiring a blue vs green discrimination were solved most rapidly (Table 1 ).

The data of the present study indicate that prairie dogs possess a mechanism for color vision which is sensitive to a wide range of wavelengths. It is highly unlikely that these animals were responding to brightness cues since great care was taken to control for this factor. Transmittance of the neutral density filters employed ranged from $10 \%$ to $80 \%$, and some

Table 1

\begin{tabular}{|c|c|c|c|c|}
\hline $\begin{array}{c}\text { Subject } \\
\text { No. }\end{array}$ & $\begin{array}{c}\text { Order } \\
\text { of } \\
\text { Problem }\end{array}$ & Discrimination & $\begin{array}{l}\text { Errors } \\
\text { to } \\
\text { Criterion }\end{array}$ & $\begin{array}{l}\text { Days } \\
\text { to } \\
\text { Criterion }\end{array}$ \\
\hline 1 & 1 & Red $(+)$ vs Yellow $(-)$ & 44 & 3 \\
\hline 1 & 2 & $\operatorname{Red}(+)$ vs Green $(-)$ & 4 & 1 \\
\hline 1 & 3 & $\operatorname{Red}(+)$ vs Blue $(-)$ & 2 & 1 \\
\hline 1 & 4 & $\operatorname{Red}(+)$ vs White $(-)$ & 4 & 1 \\
\hline 2 & 1 & Yellow $(+)$ vs Red (-) & 57 & 4 \\
\hline 2 & 2 & Yellow (+) vs Blue (-) & 3 & 1 \\
\hline 2 & 3 & Yellow (+) vs Green (-) & 43 & 3 \\
\hline 2 & 4 & Yellow (+) vs White (-) & 2 & 1 \\
\hline 3 & 1 & Green $(t)$ vs Blue $(-)$ & 13 & 2 \\
\hline 3 & 2 & Green (+) vs Red (-) & 4 & 1 \\
\hline 3 & 3 & Green $(+)$ vs Yellow $(-)$ & 117 & 8 \\
\hline 3 & 4 & Green $(+)$ ys White $(-)$ & 5 & 1 \\
\hline 4 & I & Blue $(t)$ vs Green $(-)$ & 16 & 2 \\
\hline 4 & 2 & Blue $(+)$ vs Yellow $(-)$ & 0 & 1 \\
\hline 4 & 3 & Blue $(+)$ vs Red (-) & 1 & 1 \\
\hline 4 & 4 & Bhe $(+)$ vs White $(-)$ & 1 & 1 \\
\hline
\end{tabular}




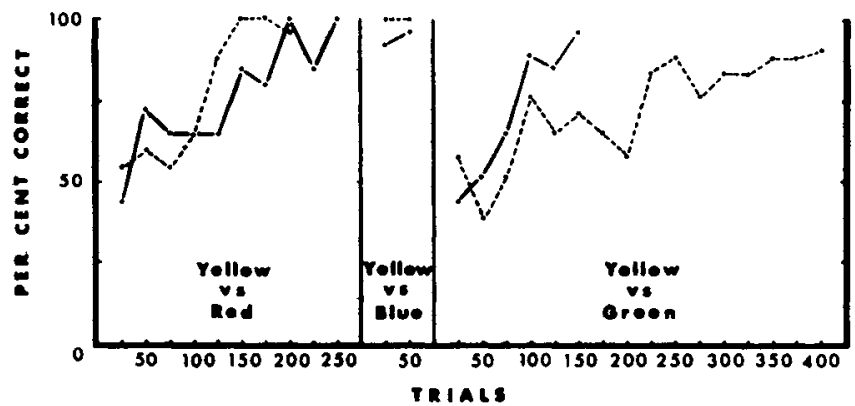

Fig. 1. Percentages of correct responses. The dotted lines depict performance when yellow was negative; the solid lines indicate yellow as positive.

trials included no neutral density filters, further extending the range of transmittance. Also, a sufficient number of different filters were used to guard against the possibility that particular intensities might be learned. It may be argued, however, that the brightness levels may not have been truly random since intensity was matched only on a physical scale and not for the animal. But, even if this were true, brightness was varied over sufficient range to assure that criterion could not be reached on the basis of brightness cues alone.

Further evidence that militates against the hypothesis that the discriminations were solved by brightness cues is the fact that performance on the yellow vs green problems dropped to chance for a short time (Fig. 1). When this problem was introduced it included only one new color while the old color remained positive at the same brightness level. If brightness were the basis for discrimination. the transfer from a yellow vs blue to a yellow vs green problem should not have caused such an abrupt drop in performance. The fact that performance did not drop to chance when the other problems were introduced could mean the animals were learning to respond to particular levels of brightness, but it should be recalled that the same color was rewarded in each problem; therefore, with the addition of only one new (unrewarded) color an extreme change in performance should not occur.

Walls (1942) reports that the lens of the prairie dog's eye is markedly yellow in color. Since a yellow lens would strongly absorb the shorter wavelengths, difficulty with those problems involving the blue filter might be expected. The present data. however. indicate that blue was easily discriminated from each of green. yellow, red, and white. In fact. performance on these problems was actually superior to most nonblue discrininations (Table 1). These high performance levels with the blut filter could possibly be explained in terms of increased sensitivity to certain wavelengths. Spectral sensitivity curves for the souslik (Citellus citellus) have indicated the existence of photoreceptors with maximum sensitivities of 470-520 $\mathrm{m} \mu$ (Arden \& Tansley, 1955b). Michael (1966) reported that the ground squirrel, Citellus mexicamis, possessed photoreceptors which were sensitive to blue and green wavelengths. No spectral sensitivity curves for prairie dogs have been reported, but it is possible that they possess photoreceptors similar to those of ground squirrels. If such blue and green mechanisms exist in prairie dogs, discriminations involving these colors should be relatively easy. The data, in fact. did indicate that all blue discriminations were easily solved, but green vs yellow discriminations were difficult. Perhaps the difficulty with yellow vs green problems were due to the relatively narrow spectral differences of the yellow and green filters confounded with the yellow lens of these sciurids.

\section{REFERENCES}

ARDEN, G. B., \& SILVER, P. H. Visual thresholds and spectral sensitivities of the grey squirrel (Sciunus carolinensis leucotis). Journal of Physiology, 1962, 163, 540-557.

ARDEN, G. B., \& TANSLEY, K. The spectral sensitivity of the pure-cone retina of the souslik (Citellus citellus). Journal of Physiology, 1955b, 130, 225-232.

CRESCITELLI, F., \& POLLACK, J. D. Color vision in the Antelope ground squirrel. Science, 1965, 150, 1316-1318.

GELLERMAN, L. W. Chance orders of alternating stimuli in visual discrimination experiments. Journal of Genetic Psychology, 1933, 42, 206-208.

MICHAEL, C. R. Receptive fields of opponent color units in the optic nerve of the ground squirrel. Science, 1966, 152, 1095-1097.

MICHELS, K. M., \& SCHUMACHER, A. W. Color vision in tree squirrels Psy chonomic Science, 1968, 10, 7-8.

REUCK, A. V. S., \& KNIGHT, J. Colour vision, physiology, and experimental psychology. Boston: Little, Brown, \& Co., 1965.

TANSLEY, K., COPENHAVER, R. M., \& GUNKEL, R. D. Spectral sensitivity curves of diurnal squirrels. Vision Research, 1961, 1 154-165.

WALLS, G. L. The vertebrate eye. Bloomfield Hills: The Cranbrook Press, 1942.

NOTE

1. This study was supported by Texas state research funds. 